\title{
Characterization of the Colonic Response to Bisacodyl in Children with Treatment-Refractory
}

\section{Constipation}

Running title:

Bisacodyl in Children with Constipation

Authors:

Paul T Heitmann ${ }^{1}$, Lukasz Wiklendt ${ }^{1}$, Nikhil Thapar ${ }^{2}$, Osvaldo Borrelli ${ }^{2}$, Carlo Di Lorenzo ${ }^{3}$, Desalegn T Yacob ${ }^{3}$, Desiree F Baaleman ${ }^{3}$, Mana H Vriesman ${ }^{3,6}$, Samuel Nurko ${ }^{4}$, Khalil El-Chammas ${ }^{5}$, Ajay Kaul $^{5}$, Marc A Benninga ${ }^{6}$, Ilan JN Koppen ${ }^{6}$, David A Wattchow DA ${ }^{1}$, Simon JH Brookes ${ }^{1}$, Phil G Dinning ${ }^{1}$

\section{Institution:}

${ }^{1}$ College of Medicine and Public Health \& Centre for Neuroscience, Flinders University, South Australia, Australia

${ }^{2}$ Division of Neurogastroenterology \& Motility, Department of Paediatric Gastroenterology, Great Ormond Street Hospital, and Stem Cells and Regenerative Medicine, UCL Institute of Child Health, London, United Kingdom

${ }^{3}$ Nationwide Children's Hospital, Columbus, Ohio, United States of America

${ }^{4}$ Center for Motility and Functional Gastrointestinal Disorders, Boston Children's Hospital, Boston, United States of America

${ }^{5}$ Neurogastroenterology and Motility Disorders Center, Cincinnati Children's Hospital Medical Centre, Cincinnati, Ohio, United States of America

${ }^{6}$ Amsterdam UMC, University of Amsterdam, Department of Pediatric Gastroenterology, Amsterdam, Netherlands

\section{Correspondence:}

Associate Professor Phil Dinning 
Department of Gastroenterology

Flinders Medical Centre, Flinders Drive, Bedford Park SA 5042

phil.dinning@flinders.edu.au

Author contributions:

PH, PD, SB and DW were responsible for study concept and design, data analysis, interpretation of analysis, drafting of the manuscript; DY, DB, MV, KE, and IK were responsible for data acquisition; $\mathrm{NT}, \mathrm{OB}, \mathrm{CL}, \mathrm{SN}, \mathrm{AK}$, and $\mathrm{MB}$ were responsible clinical supervision and patient care, and critical manuscript review; LW wrote the software for the analysis of manometry data and contributed to the statistical analysis and graphical representation of data. All authors provided critical revision of the manuscript. 


\section{Abstract}

Background: Colonic manometry with intraluminal bisacodyl infusion can be used to assess colonic neuromuscular function in children with treatment-refractory constipation. If bisacodyl does not induce high-amplitude propagating contractions (HAPCs), this can be an indication for surgical intervention. A detailed characterisation of the colonic response to intraluminal bisacodyl in children with constipation may help to inform clinical interpretation of colonic manometry studies. Methods: Studies were performed in five paediatric hospitals. Analysis included identification of HAPCs, reporting HAPCs characteristics, and an area under the curve (AUC) analysis. Comparisons were performed between hospitals, catheter type, placement techniques, and site of bisacodyl infusion. Results: 165 children were included (median age 10, range 1-17 years; $n=96$ girls). 1893 HAPCs were identified in 154 children $(12.3 \pm 8.8 \mathrm{HAPCs} / \mathrm{child}, 0.32 \pm 0.21 \underline{\mathrm{HAPCs} / \mathrm{min}}$; amplitude $113.6 \pm 31.5 \mathrm{mmHg}$; velocity $8.6 \pm 3.8 \mathrm{~mm} / \mathrm{s}$, propagation length $368 \mathrm{~mm} \pm 175 \mathrm{~mm}$ ). The mean time to first HAPC following bisacodyl was $553 \mathrm{~s} \pm 669 \mathrm{~s}$. Prior to the first HAPC, there was no change in AUC when comparing pre- vs postbisacodyl $(Z=-0.53, p=0.60)$. The majority of HAPCs terminated in a synchronous pressurization in the rectosigmoid. Defecation was associated with HAPCs $\left(\chi^{2}(1)=7.04, p<0.01\right)$. Site of bisacodyl administration, catheter type, and hospital location did not alter the response. Conclusions \& Inferences: Intraluminal bisacodyl induced HAPCs in $93 \%$ of children with treatment-refractory constipation. The bisacodyl response is characterised by $\geq 1$ HAPC within 12 minutes of infusion. The majority of HAPCs terminate in a synchronous pressurization in the rectosigmoid. Optimal clinical management based upon colonic manometry findings is yet to be determined.

\section{Key words}

Constipation, Bisacodyl, Children, Manometry 


\section{Introduction}

Constipation is one of the most common gastrointestinal symptoms $(1,2)$. In both adults and children with constipation, colonic manometry studies have recorded abnormal colonic contractile responses to meals and morning awakening(3-5). However, these responses remain poorly defined, even in healthy adults. Chemical stimuli can induce distinctive, rapid colonic responses that allow researchers and clinicians to assess colonic neuromuscular function. Of particular diagnostic interest is the colonic response to intraluminal infusion of bisacodyl.

Bisacodyl is a stimulant laxative, belonging to the group of diphenylmethanes. In the colon, diphenylmethanes are hydrolyzed to their active metabolites, which are hypothesized to exert a local prokinetic effect(6-8) and stimulate intestinal secretion $(6,9,10)$. Application of bisacodyl to the colonic mucosa induces rapid, distinctive propagating motor patterns (11), which have been labelled 'highamplitude propagating contractions' (HAPCs) (12).

In some tertiary/quaternary pediatric hospitals, colonic manometry with intraluminal bisacodyl infusion is used as a diagnostic modality to assess colonic neuromuscular function in children with treatmentunresponsive (refractory) constipation(13-18). There are some site-specific differences in equipment and study protocol, including; (1) water-perfused or solid-state catheters, (2) variable sensor count and resolution/spacing, and (3) catheter placement techniques, all of which could influence results. Initiation of HAPCs following bisacodyl is considered to be a "normal" colonic response(19-24). A diagnosis of an "abnormal" bisacodyl response has a significant bearing on the clinical course of the child, as it can be an indication for surgical intervention(17, 19, 25-29). Surgical management can include anal sphincter botulinum toxin injection(30), caecostomy/appendicostomy for administration of antegrade continence enemas $(26,31)$, colonic diversion via an ileostomy or colostomy $(28,32)$, and/or partial/total colectomy $(33,34)$.

Given the importance of the colonic response to intraluminal bisacodyl in children, a detailed characterization of the induced motor patterns is critical to inform the interpretation of these findings. 
Previous smaller studies have reported the time interval between bisacodyl administration and the first HAPC, as well as the amplitude and frequency of HAPCs $(35,36)$. The "completeness" of the HAPCs is also described, with previous studies demonstrating that HAPCs terminating $>15 \mathrm{~cm}$ from the anal verge may be pathological(37). The colonic bisacodyl response is comparable when bisacodyl is infused into the left $(38,39)$ or right $(5)$ hemicolon, and is dose-dependent; with higher doses of bisacodyl being associated with an increase in length of HAPC propagation and total HAPC count(40).

In this study, we have collated colonic manometry data from five tertiary/quaternary paediatric hospitals in the United States of America (USA), the United Kingdom (UK), and the Netherlands (NL), with the aim of characterising the colonic response to intraluminal infusion of bisacodyl in children with treatment-refractory constipation. In addition, we assessed whether hospital site, catheter type, placement technique, or site of drug administration had any influence upon the recorded colonic response.

\section{Methods}

This study involved a retrospective analysis of de-identified clinical data. Local institution review board approval was granted. A data sharing agreement between the participating hospitals was enacted in accordance with US legislation (HIPAA).

Children referred to a tertiary paediatric hospital for investigation of constipation refractory to intensive medical treatment were included in the study. This included a variable combination of osmotic and stimulant laxatives (bisacodyl, polyethylene glycol with electrolytes, sodium picosulfate, prucalopride, lubiprostone, senna, lactulose, magnesium oxide, magnesium citrate, psyllium husk, and/or prunes/prune juice), in conjunction with per rectal enemas and/or rectal irrigation.

Colonic manometry studies were performed at five tertiary paediatric hospitals; Great Ormond Street Hospital, UK, Nationwide Children's Hospital, USA, Boston Children's Hospital, USA, Cincinnati 
Children's Hospital Medical Centre, USA, and the Emma Children's Hospital, Amsterdam UMC, NL.

Data analysis was performed at Flinders University, Australia.

Catheter placement was achieved using either;

1) Colonoscopy, performed under general anaesthesia with propofol. A snare was passed through the biopsy channel of the colonoscope to grasp a suture loop attached to the tip of the catheter. The catheter was then placed under direct vision and, in some instances, fixed to the colonic mucosa using a haemostatic clip. Alternatively, a guide wire was advanced through the colonoscope and an exchange performed under fluoroscopy, with advancement of the catheter over the wire until it reached the cecum.

2) Fluoroscopy(41), performed under general anaesthesia with propofol. A guidewire was used to position the catheter under radiological guidance without colonoscopy. No haemostatic clips were used for fixation via this approach.

An abdominal x-ray was performed pre- and post-study to confirm catheter position. All five hospitals used high-resolution manometry catheters manufactured by Unisensor (Switzerland) and the same signal conditioning and recording equipment (MMS, The Netherlands/Laborie, Canada). All recordings were made at $10 \mathrm{~Hz}$ and prior to placement all catheters were calibrated in a pressure chamber between 0-100mmHg. The specific details of total sensor count, sensor spacing, placement techniques, and study protocol are detailed for each hospital in Table 1.

\section{Data analysis}

Analysis of colonic manometry data was performed using software (PlotHRM) developed by one of the authors (LW). PlotHRM was written in Matlab ${ }^{\odot}$ (The MathWorks, Natick, MA, USA) and JavaTM (Sun Microsystems, Santa Clara, CA, USA) and has been described in previous publications $(42,43)$. PlotHRM produces a visual display of the manometry tracing, allowing for manual identification and labelling of propagating contractions. Once a propagating contraction is labelled, PlotHRM captures the amplitude of pressure waves, length of propagation, the recording sensor at which the contractions commenced and terminated, and the velocity of propagation. 


\section{High-amplitude propagating contractions}

Manual analysis of the manometry tracings was performed in PlotHRM. All HAPCs that occurred in the pre- and post-prandial and post-bisacodyl periods were identified and labelled. Propagating pressure waves observed over $\geq 30 \mathrm{~cm}$ with an amplitude $\geq 75 \mathrm{mmHg}$ were classified as HAPCs(44).

\section{Colonic motor patterns}

$\underline{\text { In children with an absence of HAPCs, visual identification and labelling of other recognised colonic }}$ motility patterns was performed to assess the presence of any contractile activity. This included identification of low-amplitude propagating contractions(43). Low-amplitude propagating contractions were classified as propagating contractions that did not meet the amplitude criteria for HAPCs.

\section{Statistics}

Descriptive statistics were reported for patient demographics, catheter type, catheter placement approach, site of bisacodyl infusion, frequency of positive tests, time from bisacodyl infusion to first HAPC (mean \pm SD), characteristics of HAPCs (count, frequency, velocity, amplitude, and length of propagation), and whether or not the child defecated during the study. As there were differences in catheter length and the location of the most proximal sensor (cecum, ascending, transverse, descending, or sigmoid colon), the recorded length of propagation may not be a true representation of the full length of propagation. As such we refer to the minimum propagation distance.

A Pearson's chi-squared test was used to determine the relationship of HAPCs to defecation. The site of catheter position/bisacodyl infusion (cecum/ascending colon, transverse colon, descending/sigmoid colon) was used as a comparison for mean time between bisacodyl infusion and first HAPC. These data were not normally distributed (Shapiro-Wilk test $\mathrm{p}<0.01$ ), so a non-parametric analysis (Kruskall-Wallis H test) was used. 
Subgroup analyses were performed to compare results from (1) the five hospital sites, (2) catheter type (water-perfused/solid state), (3) catheter placement approach (retrograde per anal/per stomal or antegrade per appendicostomy/cecostomy), (4) inclusion of sodium picosulfate in bowel preparation, and (5) children with Hirschsprung's disease following surgical resection of the affected colonic

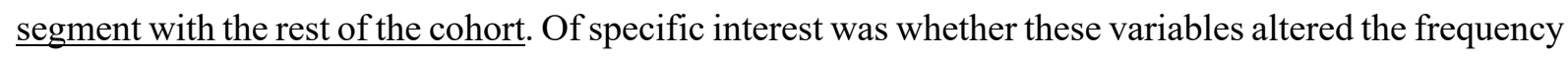
of positive tests (Pearson's chi-squared test), HAPC amplitude (independent t-test/one-way ANOVA), and the total HAPC count (Shapiro-Wilk test $\mathrm{p}<0.01$, Mann-Whitney $\mathrm{U}$ test/Kruskal-Wallis H test).

Statistical analysis was performed using IBM SPSS (Version 19.0, Released 2010; IBM Corp., Armonk, New York, USA). A p-value of $\leq 0.05$ was considered statistically significant. $\underline{\text { Bonferroni correction was }}$ applied to multiple statistical comparisons.

\section{Area under the curve analysis}

In addition to the characterisation of HAPCs, an area under the curve analysis was used to determine whether bisacodyl induced any change in colonic phasic activity prior to the first HAPC. The manometry trace was divided into ten 60 -second epochs pre-bisacodyl and compared to the 60 -second epochs postbisacodyl, prior to the first HAPC (up to 10 minutes if no HAPCs occurred; Shapiro-Wilk test $\mathrm{p}<0.01$, Wilcoxon signed-rank test).

\section{Results}

\section{Demographics}

A total of 165 pediatric colonic manometry studies were included (Great Ormond Street Hospital $n=43$, Nationwide Children's Hospital n=38, Boston Children's Hospital n=36, Cincinnati Children's Hospital Medical Centre n=25, Emma Children's Hospital, AUMC n=23). All children underwent investigation for constipation refractory to intensive medical treatment. Eighteen children had a confirmed previous diagnosis of Hirschsprung's disease on colonic biopsy, with the affected segment surgically resected prior to this study (pull-through procedure $n=12$, colectomy with end colostomy formation $n=4$, not 
specified $n=2)$. Complete medication history data was available for 47 children, of which 22 children were receiving regular bisacodyl prior to their study.

Median age was 10 years (range 1-17 years), with 96 girls (58.2\%) and 69 boys (41.8\%). Sixty-six studies (40.0\%) were performed with water-perfused catheters and $99(60.0 \%)$ with solid-state catheters. Catheter placement was via either a retrograde approach (per rectal $n=144$ or per colostomy $n=5$ ) or antegrade approach (per appendicostomy/cecostomy $n=16$ ). With catheters placed either through the appendicostomy/cecostomy, and those placed via a retrograde approach to the cecum, bisacodyl was infused into the cecum $(n=49,29.7 \%)$. In the remaining studies, bisacodyl was infused through the catheter tip into the ascending colon $(n=53,32.1 \%)$, transverse colon $(n=36,21.8 \%)$, descending colon $(\mathrm{n}=22,13.3 \%)$, or sigmoid colon $(\mathrm{n}=5,3.0 \%)$.

\section{High-amplitude propagating contractions}

Prior to bisacodyl infusion, spontaneous HAPCs were identified in 59 children (35.8\%) during the postprandial period. In 28 of these children (17.0\% overall), spontaneous HAPCs were additionally observed whilst fasting. HAPCs were induced following bisacodyl in 154 children (93.3\%, population estimate Wilson's $95 \% \mathrm{CI} 88.5 \%, 96.2 \%$ ) at a mean time interval of $553 \mathrm{~s} \pm 669 \mathrm{~s}$ (range $=10 \mathrm{~s}-4343 \mathrm{~s}$ ) post-infusion. In the majority of children (122/154, 79.2\%), the first HAPCs were recorded within 12 minutes of bisacodyl infusion (Fig 2). Of the eleven children that did not generate a HAPC pre- or postbisacodyl (Fig 3), 10/11 demonstrated low amplitude propagating sequences $(2,5,22)$. Two of these eleven children were those with a previous colonic resection for Hirschsprung's disease.

A total count of 1893 post-bisacodyl HAPCs were identified, all propagating in an antegrade direction. The mean count per patient was $12.3 \pm 8.8 \mathrm{HAPCs}$, at a frequency of $0.32 \pm 0.21 / \mathrm{min}$. Mean amplitude was $113.6 \pm 31.5 \mathrm{mmHg}$, at a velocity of $8.6 \pm 3.8 \mathrm{~mm} / \mathrm{sec}$, with a minimum propagated distance of $368 \mathrm{~mm} \pm 175 \mathrm{~mm}$ 
Of the 1893 HAPCs, 337 (17.8\%) propagated along the entire length of the catheter. The majority of HAPCs $(82.2 \%, 1556 / 1893$ total count) terminated prior to the distal recording sensors (Fig 1). Of the partially-propagating HAPCs, $69.5 \%(\mathrm{n}=1082)$ terminated in a synchronous pressurization across the distal channels (mean distance $=288 \mathrm{~mm} \pm 165 \mathrm{~mm})($ Fig 1$)$. These appeared to be analogous to the subtype of pancolonic pressurizations associated with propagating sequences described by Corsetti et $\mathrm{al}(45)$. Using pre- and post-study $\mathrm{x}$-ray imaging to localise sensor location(37), the termination of these HAPCs occurred most commonly in the sigmoid colon $(n=46,59.7 \%$; transverse colon $n=14,18.2 \%$; descending colon $n=14,18.2 \%$; rectum $n=3,3.9 \%)$.

\section{Comparison between pre-bisacodyl and post-bisacodyl high-amplitude propagating contractions}

When comparing the spontaneous pre-bisacodyl HAPCs and post-bisacodyl HAPCs, there were significant differences observed in several characteristics including higher amplitude, length of propagation, and frequency in the post-bisacodyl group (see Table 2). There were no significant differences in HAPC velocity (Table 2).

\section{Defecation}

During the post-bisacodyl infusion period, defecation was induced in $80.6 \%$ of children $(n=58 / 72)$. Defecation was significantly associated with the presence of HAPCs $\left(\chi^{2}(1)=7.04 p=0.008\right.$, Bonferroniadjusted $\alpha=0.0083(0.05 / 6))$. There were no differences in characteristics of HAPCs when comparing those associated with defecation with those not associated with defecation (frequency $U=163, \mathrm{p}=0.04$; amplitude $\mathrm{t}(13.76)=2.32, \mathrm{p}=0.04$; count $U=226, \mathrm{p}=0.37$; velocity $U=189, \mathrm{p}=0.12$; length of propagation $U=244, \mathrm{p}=0.57$; Bonferroni-adjusted $\alpha=0.0083(0.05 / 6))$.

\section{Anatomical site of bisacodyl administration}

The mean time to the first HAPC appeared to be more rapid when bisacodyl was administered more distally, however this difference did not reach significance $\left(\chi^{2}(3)=3.66, p=0.30\right.$; mean time to first HAPC following bisacodyl infusion into cecum/ascending colon $=632 \mathrm{~s} \pm 790 \mathrm{~s}, \mathrm{n}=99$; transverse 
colon=456s $\pm 341 \mathrm{~s}, \mathrm{n}=30$; descending colon=375s $\pm 323 \mathrm{~s}, \mathrm{n}=21$; sigmoid colon $282 \pm 114 \mathrm{~s}, \mathrm{n}=4$ ) (Fig 4).

\section{Area under the curve analysis}

The area under the curve analysis (Fig 5) demonstrated no significant change in phasic activity in the 10 minutes pre- and post-infusion, prior to the first $\operatorname{HAPC}(Z=-0.53, \mathrm{p}=0.60)$.

\section{Subgroup analyses}

\section{Hospital site}

When comparing the five hospital sites, there were no significant differences in the number of tests with bisacodyl-induced HAPCs $\left(\chi^{2}(4)=7.56, \mathrm{p}=0.11\right)$ or HAPC amplitude $(F(4,149)=1.09, \mathrm{p}=0.36)$. There was a significant difference in total HAPC count $\left(\chi^{2}(4)=26.45, p<0.001\right.$; Bonferroni-adjusted $\alpha=0.0125$ $(0.05 / 4))$ between the five hospital sites. However, this is likely to have been influenced by the duration of recording following bisacodyl infusion, which also differed significantly between hospital sites $\left(\chi^{2}(4)=78.66, p<0.001 ;\right.$ Bonferroni-adjusted $\alpha=0.0125(0.05 / 4)$; Great Ormond Street Hospital $=129$ \pm 46 mins; Boston Children's Hospital $=121 \pm 47$ mins; Emma Children's Hospital $=42 \pm 17$ mins; Nationwide Children's Hospital $=75 \pm 26$ mins; Cincinnati Children's Hospital Medical Centre $=86 \pm$ 26 mins)

\section{Solid state/water-perfused catheters}

When comparing solid-state and water-perfused catheters, there were no significant differences in the number of tests with bisacodyl-induced HAPCs $\left(\chi^{2}(1)=0.26, p=0.61\right)$, HAPC amplitude $t(152)=-1.73$, $\mathrm{p}=0.09$, or total HAPC count $(U=2790, \mathrm{p}=0.91)$.

\section{Catheter placement approach}

When comparing antegrade and retrograde catheter placement, there was a statistically significant difference in the number of tests without post-bisacodyl HAPCs $\left(\chi^{2}(1)=9.57, p=0.002\right.$, Bonferroniadjusted $\alpha=0.017(0.05 / 3))$. One quarter of tests performed in children with antegrade catheter 
placement (4/16) demonstrated no post-bisacodyl HAPCs, compared with 4.7\% (7/149) in the children with retrograde catheter placement. There were no significant differences in HAPC amplitude $(\mathrm{t}(152)=1.36, \mathrm{p}=0.18)$, or total HAPC count $(U=625, \mathrm{p}=0.13)$ when comparing catheter placement approach.

\section{Hirschsprung's disease}

When comparing the children who had previously undergone surgical resection for Hirschsprung's disease ( $n=18)$ with the rest of the cohort $(n=147)$, there were no significant differences in the number of tests with bisacodyl-induced HAPCs $\left(\chi^{2}(1)=0.64, p=0.42\right)$, HAPC amplitude $t(152)=1.37, p=0.17$, or total HAPC count $(U=741, \mathrm{p}=0.03$, Bonferroni-adjusted $\alpha=0.017(0.05 / 3))$.

\section{Sodium picosulfate}

Five children (3.0\%) received sodium picosulfate as a component of bowel preparation prior to their colonic manometry study. Sodium picosulfate, similar to bisacodyl, is a pro-drug and metabolises to the same active chemical within the colon (bis-(p-hydroxyphenyl)-pyridyl-2-methane). As such, an additional analysis was performed on this subgroup to assess whether administration of sodium picosulfate prior to investigation diminished the bisacodyl response. All five of these children demonstrated HAPCs post bisacodyl, commencing at 31-344s post infusion (compared with mean time 553s overall).

\section{Discussion}

Following bisacodyl infusion, the majority of children (93.3\%) with severe, intractable constipation are capable of generating HAPCs. In 79\% of these children, the first HAPC occurs within 12 minutes. The majority of HAPCs propagate for a partial length of the manometry catheter only, with most terminating in a synchronous pressurization in the rectosigmoid. An absence of HAPCs was only observed in 11 children (6.7\%). Bisacodyl also appears to induce an all-or-nothing colonic response, with no change in phasic activity prior to the first HAPC. These findings also demonstrate that catheter type, site of bisacodyl infusion, and hospital site do not influence the recorded colonic response. 
The colonic response was independent of the anatomical site of bisacodyl administration. While there was a trend towards a more rapid response with more distal administration, this did not reach significance (Fig 4). The mechanisms by which bisacodyl induces HAPCs is incompletely understood. It has been suggested that bisacodyl may increase luminal secretion $(6,9,10)$, and/or decrease water absorption(46). These effects may, in turn, play a role in inducing HAPCs. However, given the brief interval between drug administration and HAPCs, these mechanisms are unlikely to account for the response seen in these data. A more direct pathway has been proposed, whereby bisacodyl acts via excitation of colonic smooth muscle via tetrodoxin-insensitive, nifedipine-sensitive pathways(6-8). Bisacodyl is converted into an active metabolite bis-(p-hydroxyphenyl)-pyridyl-2-methane (BHPM) via esterase enzymes in the colonic mucosa(47) and there is minimal systemic absorption (48). The action of bisacodyl can be blocked by a prior application of lignocaine to the colonic mucosa(11). Collectively, these findings may suggest that bisacodyl causes excitation of extrinsic sensory nerves and the subsequent activation of parasympathetic innervation to the proximal colon.

Our data included a high prevalence of partially propagating HAPCs which terminated in a synchronous pressurization. It has been suggested that, in children, partial propagation of HAPCs is associated with slow colonic transit(49) and segmental colonic dilation(37). However, synchronous pressurizations at the termination of HAPCs are also hypothesized to function as a means to maintain colonic wall tone to facilitate transit in health $(45,50)$. Corsetti et al(45) identified pressurizations at the termination of $74 \%$ of propagating contractions in the prandial period in healthy adults. This is a similar frequency to the $82 \%$ observed in the post-bisacodyl period in our sample. Therefore, the significance of this finding remains uncertain and further studies with functional correlation are required.

Colonic pressurizations can also be induced with intraluminal bisacodyl in both adult and paediatric patients with severe constipation $(22,39,45)$. In these data, pancolonic pressurizations were not present after intraluminal bisacodyl. During the bisacodyl-evoked HAPCs, all other motor patterns appeared to 
be suppressed. Therefore, in these children, the presence or absence of HAPCs alone appeared to be sufficient to define the colonic response to bisacodyl.

Whilst pharmacological induction of HAPCs using bisacodyl does not replicate normal colonic physiology, previous smaller studies have reported that no significant differences in the characteristics (frequency, amplitude, velocity, length of propagation) of spontaneous and bisacodyl-induced $\underline{\text { HAPCs}}(51)$. Having pooled data from 165 paediatric studies, our findings demonstrate that bisacodylinduced HAPCs occur with a greater frequency, are of greater amplitude, and propagate a greater distance than spontaneous HAPCs. Clinically, these findings may suggest that HAPC provocation with bisacodyl demonstrates the integrity of the enteric nervous system. This is supported by the findings in children with a confirmed prior diagnosis of Hirschsprung's disease, with the aganglionic colonic $\underline{\text { segment surgically resected prior to this study, who demonstrated a colonic response to bisacodyl which }}$ did not differ from the children without Hirschsprung's disease. Of the children without HAPCs following bisacodyl, 10/11 still demonstrated low-amplitude propagating sequences both pre- and postmeal, which have been hypothesised to be myogenic in origin(43). Given the presence of myogenic activity, but absence of HAPCs, this may support the hypothesis of colonic inertia being a neurogenic disease, assuming a neural origin of HAPCs.

Clinical decision-making regarding surgical intervention in children with constipation tends to be driven by expert opinion and varies widely between centres, with no established evidence-based guidelines(17, 31). As such, the decision to proceed with surgery is fraught with difficulties, particularly when considering the associated operative risks and irreversibility of certain procedures. $\underline{\text { In some }}$ tertiary/quaternary pediatric hospitals, colonic manometry is used to inform surgical decisionmaking $(18,28,52)$. For example, the presence of bisacodyl-provoked HAPCs on colonic manometry has been described to be predictive of a positive therapeutic response to cecostomy formation with administration of antegrade continence enemas(25). A study performed in adults with constipation also demonstrated that spontaneous and/or bisacodyl-induced HAPCs were associated with positive clinical outcomes to intensive medical treatment(53). 
Colonic manometry findings may provide more than dichotomous feedback on the presence/absence of HAPCs. Despite demonstrating an ability to generate HAPCs, children with treatment-refractory constipation may still benefit from surgical intervention due to the refractory and disabling nature of their symptoms. For example, if HAPCs do not propagate to the distal colon, and if the distal colon is dilated, these children could benefit from colonic resection in combination with a cecostomy $(37,54)$. In addition, surgical intervention may result in improved colonic motility. Following antegrade continence enemas or colonic diversion, some children with no HAPCs observed on their initial study later demonstrate HAPCs on subsequent colonic manometry studies $(28,32)$. Despite these findings, it should also be acknowledged that - at present - pediatric colonic manometry is performed in relatively few hospitals around the world. The diagnostic value of colonic manometry is yet to be determined, and this paper is not suggesting that surgical procedures should be performed solely upon the basis of colonic manometry findings.

Collating data from several countries using different catheters and placement techniques does raise several potential limitations. However, our subgroup analyses demonstrated no differences between hospital site, catheter type, or site of bisacodyl administration on the recorded colonic response. Therefore, we can infer that these variables had minimal impact on our overall findings. While there were less frequent post-bisacodyl HAPCs detected when comparing antegrade to retrograde catheter placement, this is likely to be influenced by selection bias as those who had previously undergone appendicostomy/cecostomy formation for administration of antegrade continence enemas are also likely to have greater disease severity. The sensor spacing of recording sites is also critical in colonic motor pattern detection(42). In this study, catheter sensor spacing varied between $15 \mathrm{~mm}-40 \mathrm{~mm}$. However, a previous study demonstrated that HAPCs are the only motor pattern consistently recognised regardless of the sensor spacing(42). Finally, as with all pediatric manometry studies, there is an absence of healthy age-matched control data. Despite this, we do know that bisacodyl induces HAPCs in healthy adults(36) and it is unlikely that healthy children would have a substantially different response.

\section{Conclusion}


Heitmann 16

The bisacodyl response in children with treatment-refractory constipation is characterised by an all-ornothing initiation of HAPCs. For the majority of children, the first HAPC occurs within 12 minutes of bisacodyl infusion, and terminates in a synchronous pressurization in the rectosigmoid. Catheter types, site of bisacodyl infusion, and hospital site have no significant impact upon the recording of this response. 
Acknowledgements:

Dr Heitmann is supported by the Flinders Foundation Clinician's Special Purpose Fund PhD scholarship.

Preliminary findings were presented during poster presentation sessions at Digestive Disease Week, San Diego, CA, USA, May 18-21, 2019.

The authors have no conflict of interest to declare relating to the content of this article. This is an original article which has not previously been published. 
Table 1. Details of the manometry catheters, placement techniques, and study protocol at each hospital site

\begin{tabular}{|c|c|c|c|c|c|}
\hline & $\begin{array}{l}\text { Great } \\
\text { Ormond } \\
\text { Street } \\
\text { Hospital, UK }\end{array}$ & $\begin{array}{l}\text { Nationwide } \\
\text { Children's } \\
\text { Hospital, } \\
\text { USA }\end{array}$ & $\begin{array}{l}\text { Boston } \\
\text { Children's } \\
\text { Hospital, } \\
\text { USA }\end{array}$ & $\begin{array}{l}\text { Cincinnati } \\
\text { Children's } \\
\text { Hospital } \\
\text { Medical } \\
\text { Centre, USA }\end{array}$ & $\begin{array}{l}\text { Emma } \\
\text { Children's } \\
\text { Hospital, NL }\end{array}$ \\
\hline $\begin{array}{l}\text { Diet for } 24 \\
\text { hours prior to } \\
\text { study }\end{array}$ & $\begin{array}{l}\text { Liquid, low- } \\
\text { residue diet }\end{array}$ & Clear fluids & Clear fluids & Clear fluids & Clear fluids \\
\hline $\begin{array}{l}\text { Bowel } \\
\text { preparation }\end{array}$ & $\begin{array}{l}\text { PEG-3350 } \\
\text { with } \\
\text { electrolytes }\end{array}$ & $\begin{array}{l}\text { PEG-3350 } \\
\text { with } \\
\text { electrolytes } \\
\text { +/- mineral oil } \\
\text { enema }\end{array}$ & $\begin{array}{l}\text { PEG-3350 } \\
\text { with } \\
\text { electrolytes }\end{array}$ & $\begin{array}{l}\text { PEG-3350 } \\
\text { with } \\
\text { electrolytes } \\
\text { +/- rectal } \\
\text { lavage }\end{array}$ & $\begin{array}{l}\text { PEG-3350 } \\
\text { with } \\
\text { electrolytes } \\
\text { +/- sodium } \\
\text { picosulfate }\end{array}$ \\
\hline $\begin{array}{l}\text { Manometry } \\
\text { sensor count }\end{array}$ & 20 sensors & 36 sensors & 36 sensors & 36 sensors & 36 sensors \\
\hline $\begin{array}{l}\text { Manometry } \\
\text { sensor spacing }\end{array}$ & $25 \mathrm{~mm}$ & $30 \mathrm{~mm}$ & $30 \mathrm{~mm}$ & $\begin{array}{l}20 \mathrm{~mm}-40 \mathrm{~mm} \\
\text { (proximal } \\
\text { sensors } 1-20= \\
40 \mathrm{~mm} \text {, distal } \\
\text { sensors } 21-36 \\
=20 \mathrm{~mm} \text { ) }\end{array}$ & $15 \mathrm{~mm}$ \\
\hline $\begin{array}{l}\text { Solid-solid or } \\
\text { water- } \\
\text { perfused } \\
\text { catheter }\end{array}$ & $\begin{array}{l}\text { Water- } \\
\text { perfused }\end{array}$ & Solid-state & Solid-state & Solid-state & $\begin{array}{l}\text { Water- } \\
\text { perfused }\end{array}$ \\
\hline
\end{tabular}




\begin{tabular}{|c|c|c|c|c|c|}
\hline $\begin{array}{l}\text { Meal included } \\
\text { in manometry } \\
\text { study protocol }\end{array}$ & $\mathrm{Y}$ & $\mathrm{Y}$ & $\mathrm{Y}$ & $\mathrm{Y}$ & $\mathrm{Y}$ \\
\hline $\begin{array}{l}\text { Bisacodyl } \\
\text { dose }\end{array}$ & $5 \mathrm{mg}-10 \mathrm{mg}$ & $\begin{array}{l}0.2 \mathrm{mg} / \mathrm{kg} \\
(\max 10 \mathrm{mg})\end{array}$ & $\begin{array}{l}0.25 \mathrm{mg} / \mathrm{kg} \\
(\max 10 \mathrm{mg})\end{array}$ & $\begin{array}{l}0.25 \mathrm{mg} / \mathrm{kg} \\
(\max 10 \mathrm{mg})\end{array}$ & $5 \mathrm{mg}-10 \mathrm{mg}$ \\
\hline $\begin{array}{l}\text { Bisacodyl } \\
\text { administration } \\
\text { route }\end{array}$ & $\begin{array}{l}\text { Central lumen } \\
\text { of the catheter }\end{array}$ & $\begin{array}{l}\text { Central lumen } \\
\text { of the catheter } \\
\text { for retrograde } \\
\text { catheter } \\
\text { placement, or } \\
\text { into the } \\
\text { proximal } \\
\text { colon via a } \\
\text { tube placed } \\
\text { through the } \\
\text { stoma for } \\
\text { antegrade } \\
\text { catheter } \\
\text { placement }\end{array}$ & $\begin{array}{l}\text { Central lumen } \\
\text { of the catheter }\end{array}$ & $\begin{array}{l}\text { Central lumen } \\
\text { of the catheter }\end{array}$ & $\begin{array}{l}\text { Central lumen } \\
\text { of the catheter }\end{array}$ \\
\hline
\end{tabular}

Table 2. Comparisons between the characteristics of pre- and post-bisacodyl high-amplitude propagating contractions (HAPCs)

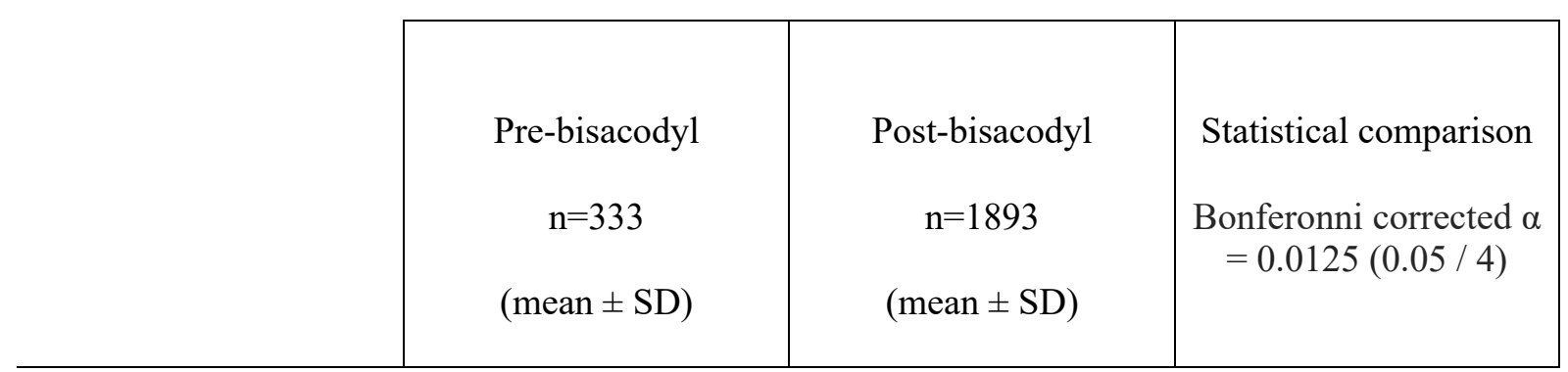


Heitmann 20

\begin{tabular}{|l|c|c|l|}
\hline $\begin{array}{l}\text { HAPC amplitude } \\
(\mathrm{mmHg})\end{array}$ & $101.2 \pm 29.2$ & $119.5 \pm 29.3$ & $\begin{array}{l}\text { Paired samples t-test; } \\
\mathrm{t}(59)=-5.06, \mathrm{p}<0.01\end{array}$ \\
\hline $\begin{array}{l}\text { Length of HAPC } \\
\text { propagation (mm) }\end{array}$ & $326 \pm 136$ & $407 \pm 189$ & Wilcoxon signed-rank \\
test; $Z=-3.75, \mathrm{p}<0.01$ \\
\hline $\begin{array}{l}\text { HAPC frequency } \\
(\text { min })\end{array}$ & $0.23 \pm 0.42$ & $0.30 \pm 0.18$ & Wilcoxon signed-rank \\
\hline $\begin{array}{l}\text { HAPC velocity } \\
(\mathrm{mm} / \mathrm{s})\end{array}$ & $11 \pm 9$ & $9 \pm 4$ & test; $Z=-4.61, \mathrm{p}<0.01$ \\
\hline
\end{tabular}




\section{References:}

1. Chitkara DK, Talley NJ, Weaver AL, et al. Incidence of presentation of common functional gastrointestinal disorders in children from birth to 5 years: a cohort study. Clin Gastroenterol Hepatol 2007; 5: 186-191.

2. Koppen IJN WL, Yacob D, et al. . Motility of the left colon in children and adolescents with functional constpation; a retrospective comparison between solid-state and water-perfused colonic manometry. Neurogastroenterol Motil 2018; 30.

3. Bassotti G, Gaburri M, Imbimbo BP, et al. Colonic mass movements in idiopathic chronic constipation. Gut 1988; 29: 1173-1179.

4. Rao SS, Sadeghi P, Beaty J, Kavlock R. Ambulatory 24-hour colonic manometry in slowtransit constipation. Am J Gastroenterol 2004; 99: 2405-2416.

5. Wessel S, Koppen IJ, Wiklendt L, Costa M, Benninga MA, Dinning PG. Characterizing colonic motility in children with chronic intractable constipation: a look beyond high-amplitude propagating sequences. Neurogastroenterol Motil 2016; 28: 743-757.

6. Krueger D DI, Ceyhan GO, Zeller F, Schemann M. bis-(p-hydroxyphenyl)-pyridyl-2-methane (BHPM) - the active metabolite of the laxatives bisacodyl and sodium picosulfate-enhances contractility and secretion in human intestine in vitro. Neurogastroent Motil 2018; 30.

7. al. SEe. The mode of action of bisacodyl on the smooth muscle of the small and the large intestine of the guinea pig. Arzneimittelforschung 1975; 25: 1053-1056.

8. al MPe. Mode of action of bisacodyl (dulcolax) on isolated muscles of human colon. Klin Wochenschr 1965; 53: 493-495.

9. K E. Effect of bisacodyl on intestinal electrolyte and water net transport and transit. Perfusion studies in men. Digestion 1987; 37: 247-253.

10. G FUN. Mechanism of action of diphenolic laxatives: the role of adenylate cyclase and mucosal permeability. Digestion 1984; 30: 191-194.

11. Hardcastle JD, Mann CV. Study of large bowel peristalsis. Gut 1968; 9: 512-520.

12. Bassotti G, Gaburri M. Manometric investigation of high-amplitude propagated contractile activity of the human colon. Am J Physiol 1988; 255: G660-664.

13. AE. B. High amplitude propagated contractions. Neurogastroenterology and motility 2012; 24: $977-982$.

14. Ravi K, Bharucha AE, Camilleri M, Rhoten D, Bakken T, Zinsmeister AR. Phenotypic variation of colonic motor functions in chronic constipation. Gastroenterology 2010; 138: 89-97.

15. G. B. If it is inert, why does it move? Neurogastroenterol Motil 2004; 16: 395-396.

16. Koppen IJ DLC, Saps M, et al. Childhood constipation: finally something is moving! . Expert Rev Gastroenterol Hepatol 2016; 10: 141-155.

17. Koppen IJ K-WS, Lu PL, Benninga MA, Di Lorenzo C, Lane VA, Levitt MA, Wood RJ, Yacob D. Surgical decision-making in the management of children with intractable functional constipation: what are we dpong and are we doing it right? Journal of Pediatric Surgery 2016; 51: 1607-1612.

18. Rodriguez L HN, Nurko S. Utility of colon manometry in guiding therapy and predicting need for surgery in children with defecation disorders. J Pediatr Gastroenterol Nutr 2019.

19. Pensabene L, Youssef NN, Griffiths JM, Di Lorenzo C. Colonic manometry in children with defecatory disorders. role in diagnosis and management. Am J Gastroenterol 2003; 98: 1052-1057.

20. Di Lorenzo C FA, Reddy SN, Hyman PE. Use of colonic manometry to differentiate causes of intractable constipation in children. J Pediatr 1992; 120: 690-695.

21. Kerur B, Kantekure K, Bonilla S, Orkin B, Flores AF. Management of chronic intractable constipation in children. J Pediatr Gastroenterol Nutr 2014; 59: 754-757.

22. Giorgio V, Borrelli O, Smith VV, et al. High-resolution colonic manometry accurately predicts colonic neuromuscular pathological phenotype in pediatric slow transit constipation. Neurogastroenterol Motil 2013; 25: 70-78 e78-79.

23. Herve S, Savoye G, Behbahani A, Leroi AM, Denis P, Ducrotte P. Results of 24-h manometric recording of colonic motor activity with endoluminal instillation of bisacodyl in patients with severe chronic slow transit constipation. Neurogastroenterol Motil 2004; 16: 397-402. 
24. Bassotti G CG, Germani U, Battaglia E, Vantini I, Morelli A. . Endoluminal instillation of bisacodyl in patients with severe (slow transit type) constipation is useful to test residual colonic propulsive activity. Digestion 1999; 60: 69-73.

25. van den Berg MM HM, Caniano DA, et al. . Colonic manometry as predictor of cecostomy success in children with defecation disorders. J Pediatr Surg 2006; 41: 730-736.

26. Rodriguez L, Nurko S, Flores A. Factors associated with successful decrease and discontinuation of antegrade continence enemas (ACE) in children with defecation disorders: a study evaluating the effect of ACE on colon motility. Neurogastroenterol Motil 2013; 25: 140-e181.

27. Di Lorenzo C, Solzi GF, Flores AF, Schwankovsky L, Hyman PE. Colonic motility after surgery for Hirschsprung's disease. Am J Gastroenterol 2000; 95: 1759-1764.

28. Villarreal J, Sood M, Zangen T, et al. Colonic diversion for intractable constipation in children: colonic manometry helps guide clinical decisions. J Pediatr Gastroenterol Nutr 2001; 33: 588-591.

29. Rodriguez L SM, Di Lorenzo C, Saps M. . An ANMS-NASPGHAN consensus document on anorectal and colonic manometry in children. Neurogastroenterol Motil 2017; 29.

30. Basson S CP, Healy C, Phelps S, Cleeve S. Botulinum toxin use in paediatric colorectal surgery. Pediatr Surg Int 2014; 30: 833-838.

31. Siminas S LP. Current Surgical Management of Pediatric Idiopathic Constipation: A Systematic Review of Published Studies. Ann Surg 2015; 262: 925-933.

32. Christison-Lagay ER RL, Kurtz M, St Pierre K, Doody DP, Goldstein AM. Antegrade colonic enemas and intestinal diversion are highly effective in the management of children with intractable constipation. J Pediatr Surg 2010; 45: 213-219.

33. Lee SL DJ, Montes-Garces RG, Inglis K, Biediger W. Surgical management of chronic unremitting constipation and fecal incontinence associated with megarectum: A preliminary report. $J$ Pediatr Surg 2002; 37: 76-79.

34. Levitt MA MC, Falcone RA, Peña A. Transanal rectosigmoid resection for severe intractable idiopathic constipation. J Pediatr Surg 2009; 44: 1285-1291.

35. Bassotti G BC, Fusaro C, Morelli A. . Colonic high-amplitude propagated contractions (mass movements): repeated 24-h manometric studies in healthy volunteers. . J Gastrointest Motil 1992; 4: $187-191$.

36. De Schryver AMP SM, Smout AJP. Effects of a meal and bisacodyl on colonic motility in healthy volunteers and patients with slow-transit constipation. Digestive Diseases and Sciences 2003; 48: $1206-1212$.

37. Koppen IJN TB, Ambeba EJ, et al. . Segmental colonic dilation is associated with premature termination of high-amplitude propagating contractions in children with intractable functional constipation. . Neurogastroenterol Motil 2017; 29.

38. King SKC-s, Anthony G; Stanton, Michael P; Sutcliffe, Jonathan R; Simpson, Dianne; et al. 24-Hour Colonic Manometry in Pediatric Slow Transit Constipation shows Significant Reductions in Antegrade Propagation. The American Journal of Gastroenterology 2008; 103: 2083-2091.

39. Kamm MA vdSJ, Lennard- Jones JE. 1992; 7: 197-201. Observations on the charac- teristics of stimulated defaecation in severe idiopathic constipation. Int J Colorectal Dis 1992; 7: 197-201.

40. Borrelli O PM, Saliakellis E, Tambucci R, Quitadamo P, Valitutti F, Rybak A, Lindley KJ, Thapar N. Sequential incremental doses of bisacosyl increase the diagnostic accuracy of colonic manometry. Neurogastroent Motil 2016; 28: 1747-1755.

41. van den Berg MM HM, Mousa HM, Di Lorenzo C. Colonic manometry catheter placement with primary fluoroscopic guidance. Dig Dis Sci 2007; 52: 2282-2286.

42. Dinning PG WL, Gibbins I, Patton V, Bampton PA, Lubowski DZ, Cook IJ, Arkwright JW. Low-resolution colonic manometry leads to a gross mis-interpretation of the frequency and polarity of propagating sequences: initial results from fibreoptic high-resolution manometry studies.

Neurogastroenterol Motil 2013; 25.

43. Dinning PG WL, Maslen L, Gibbins I, Patton V, Arkwright JW, et al. . Quantification of in vivo colonic motor patterns in healthy humans before and after a meal revealed by high-resolution fiber-optic manometry. . Neurogastroenterol Motil 2014.

44. Corsetti M CM, Bassotti G, Bharucha AE, Borrelli O, Dinning PG, Di Lorenzo C, Huizinga JD, Jimenez M, Rao SS, Spiller R, Spencer NJ, Lentle R, Pannemans J, Thys A, Benninga MA, Tack 
J. First translational consensus on terminology and definitions of colonic motility in animals and humans studied by manometric and other techniques. Nature Reviews Gastroenterology \& Hepatology 2019; 16: 559-579.

45. Corsetti M PG, Demedts I, Deloose E, Gevers A et al. Pan-colonic pressurisations associated with relaxation of the anal sphincter in health and disease: a new colonic motor pattern identified using high-resolution manometry. The American Journal of Gastroenterology 2017; 112: 479-489. 46. Ikarashi N BK, Ushiki T, Kon R, Mimura A, Toda T, Ishii M, Ochiai W et al. . The laxative effect of bisacodyl is attributable to decreased aquaporin-3 expression in the colon induced by increased PGE2 secretion from macrophages. Am J Physiol Gastrointest Liver Physiol 2011; 301: G887-895.

47. Jauch R, Hankwitz R, Beschke K, Pelzer H. Bis-(p-hydroxyphenyl)-pyridyl-2-methane: The common laxative principle of Bisacodyl and sodium picosulfate. Arzneimittelforschung 1975; 25: 1796-1800.

48. Friedrich C RE, Trommeshauser D, et al. . Absence of excretion of the active moiety of bisacodyl and sodium picosulfate into human breast milk: an open-label, parallel-group, multiple-dose study in healthy lactating women. . Drug Metab Pharmacokinet 2011; 26: 458-464.

49. Tipnis NA E-CK, Rudolph CD, Werlin SL, Sood MR. Do oro-anal transit markers predict which children would benefit from colonic manometry studies? J Pediatr Gastroenterol Nutr 2012; 54: 258-262.

50. Moreno-Osset E BG, Lo S et al. . Association between postprandial changes in colonic intraluminal pressure and transit. . Gastroenterology 1989; 96: 1265-1273.

51. Hamid SA, Di Lorenzo C, Reddy SN, Flores AF, Hyman PE. Bisacodyl and high-amplitudepropagating colonic contractions in children. J Pediatr Gastroenterol Nutr 1998; 27: 398-402.

52. Martin MJ SS, Noel JM, Weichmann D, Azarow KS. Total colonic manometry as a guide for surgical management of functional colonic obstruction: Preliminary results. J Pediatr Surg 2001; 36: 1757-1763.

53. Battaglia E GM, Dore MP, Bassotti G. Usefulness of Bisacodyl Testing on Therapeutic Outcomes in Refractory Constipation. Dig Dis Sci 2018; 63: 3105-3111.

54. Gasior A RC, Vilanova-Sanchez A, Diefenbach KA, Yacob D, Lu P, Vaz K, Di Lorenzo C, Levitt MA, Wood RJ. Surgical management of functional constipation: An intermediate report of a new approach using a laparoscopic sigmoid resection combined with malone appendicostomy. $J$ Pediatr Surg 2018; 53: 1160-1162. 
Heitmann 24
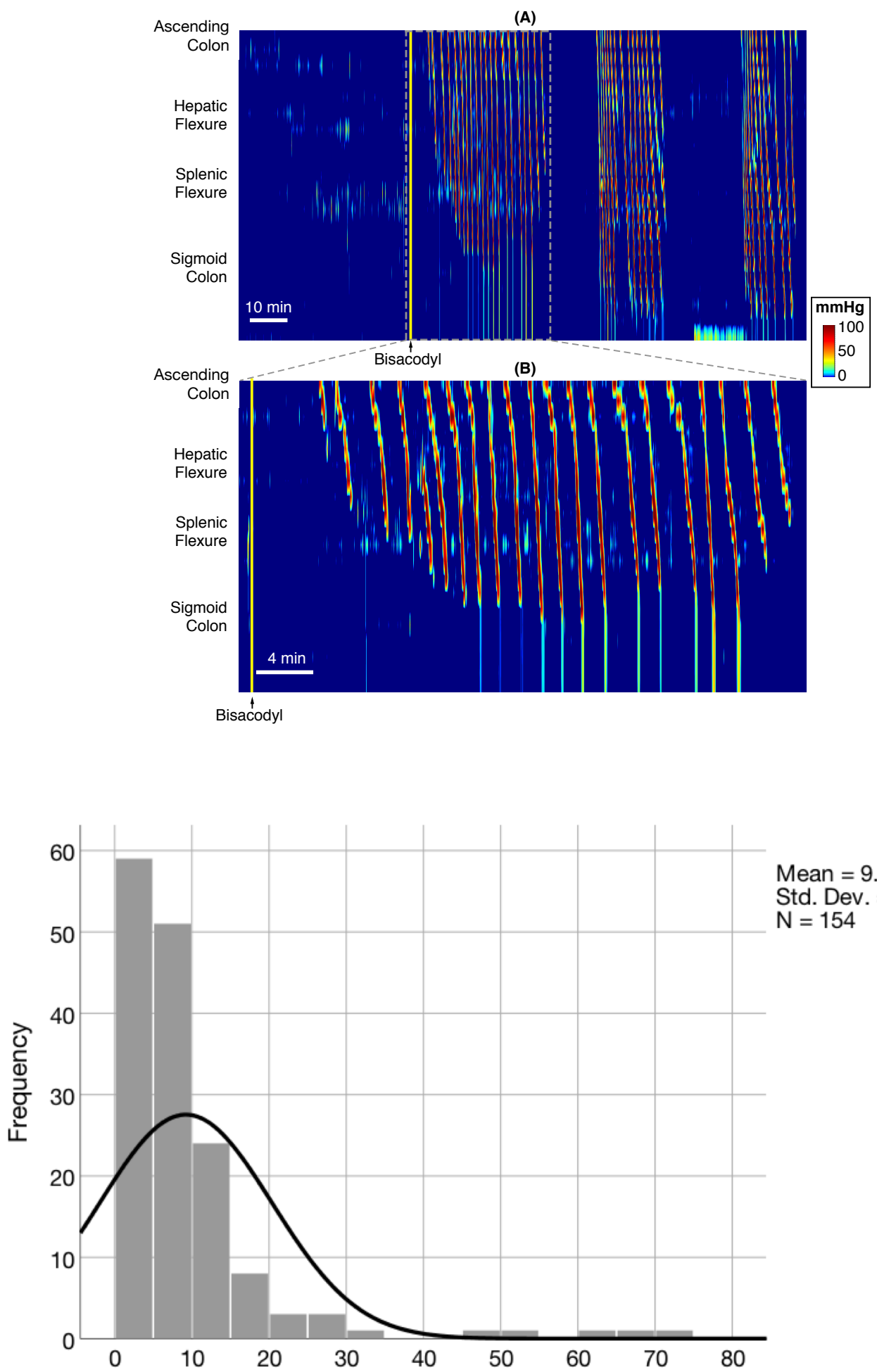

Mean $=9.22$

Std. Dev. $=11.154$ $\mathrm{N}=154$

Time to First HAPC Post-Bisacodyl Infusion (minutes) 
Heitmann 25
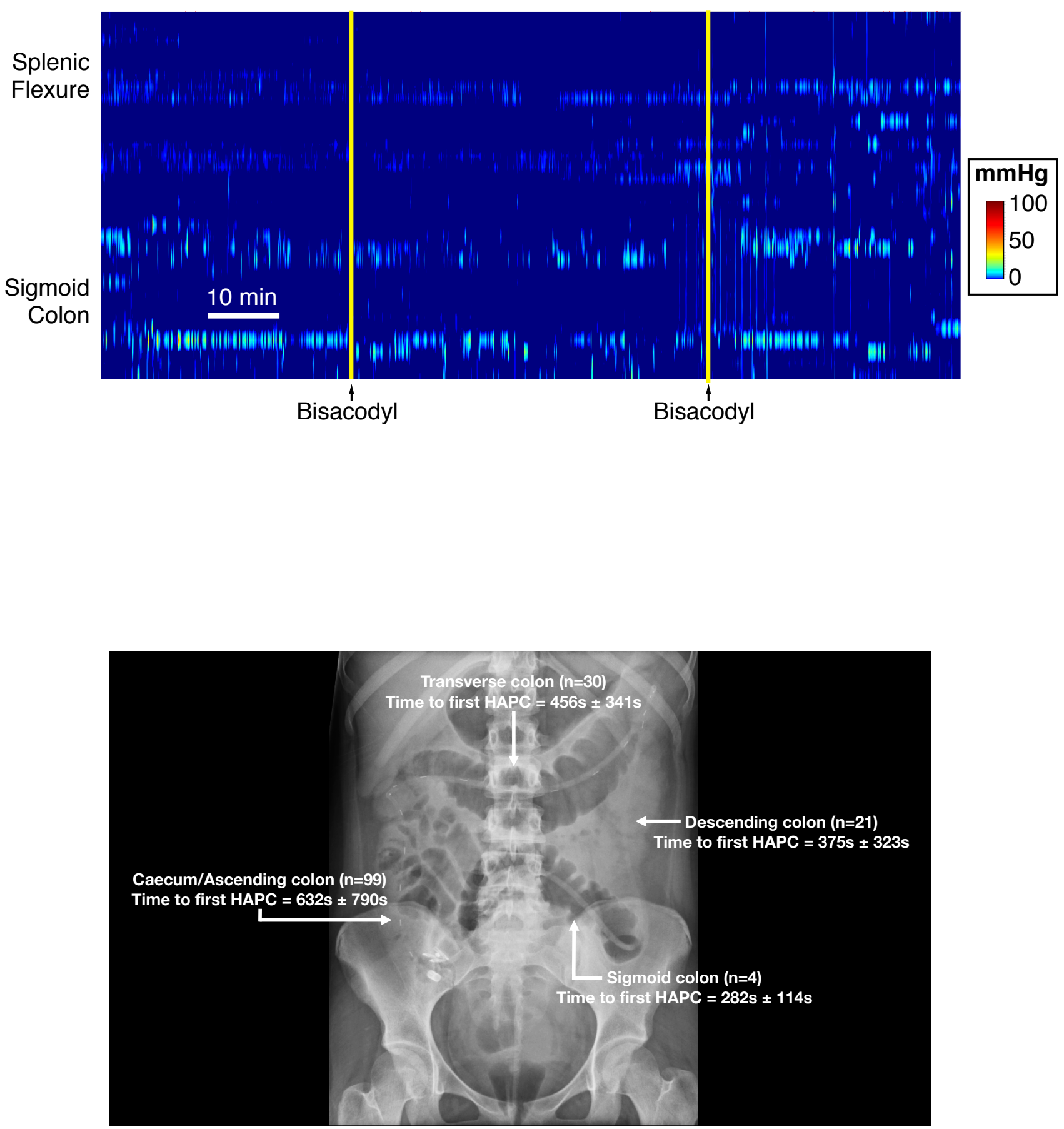
Heitmann 26

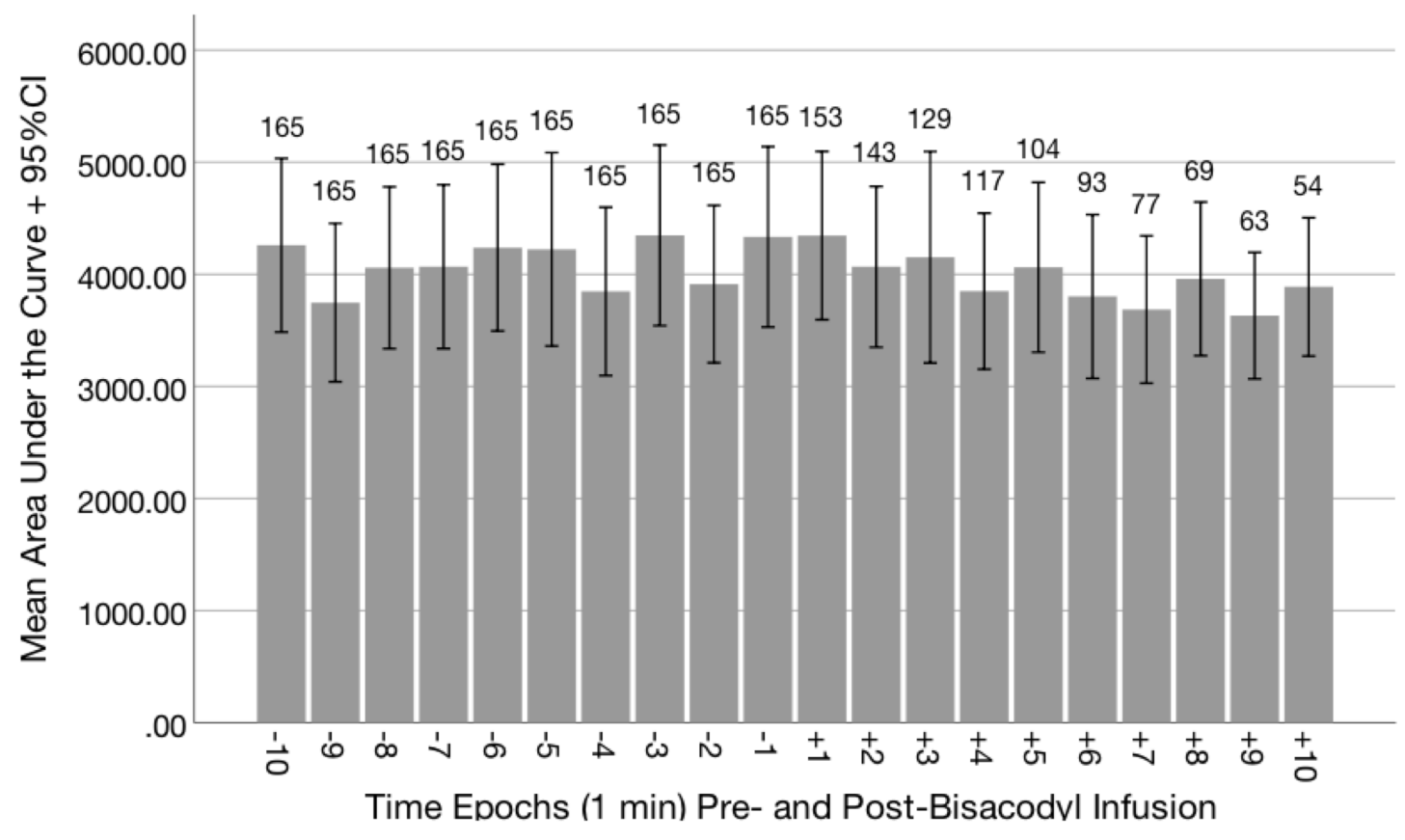

